\title{
As dificuldades de encontrar palavras: entre o som e o significado
}

DOI: http://dx.doi.org/10.21165/el.v49i2.2633

\section{Marcus Vinicius Borges Oliveira'}

\section{Resumo}

A sensação de ausência ou inacessibilidade de uma palavra que desejamos encontrar é referida na literatura científica pela sigla WFD (Word Finding Difficulties), fenômeno presente tanto na normalidade quanto em algumas patologias que impactam o funcionamento da linguagem. $O$ objetivo deste artigo é discutir criticamente a autonomia dos níveis linguísticos a partir de dados emergentes no campo das afasias. A metodologia utilizada compreende a análise microgenética de enunciados produzidos por uma senhora afásica, em contextos dialógicos. Tomando como base a Neurolinguística de orientação enunciativo-discursiva, a reflexão integra três campos de investigação científica, dentre os quais tem especial relevância a Linguística desenvolvida por Jakobson. Baseamonos também na Neuropsicologia Luriana e na Filosofia da Linguagem desenvolvida pelo Círculo de Bakhtin. Os dados apresentados e analisados deixam entrever, a partir do conceito de indissociabilidade entre som e sentido, a interdependência dos níveis linguísticos e, indo além, da multidimensionalidade presente na rede de enlaces que está subjacente a cada palavra.

Palavras-chave: afasia; linguagem; memória; tip-of-the-tongue; Word Finding Difficulties.

1 Universidade Federal da Bahia (UFBA), Salvador, Bahia, Brasil; marcus.oliveira.fono@gmail.com; https://orcid.org/0000-0001-7120-4527 


\title{
The word finding difficulties: between sound and meaning
}

\begin{abstract}
The sense of absence or inaccessibility of a word we wish to find is referred to in the scientific literature by the acronym WFD (Word Finding Difficulties), a phenomenon present both in normality and in some pathology that impact the functioning of language. This article aims to critically discuss the autonomy of language levels from emerging data in the field of aphasias. The methodology used comprises the microgenetic analysis of statements produced by an aphasic lady in dialogic contexts. Based on the enunciativediscursive neurolinguistics, the reflection integrates three fields of scientific investigation, among which has special relevance the Linguistics developed by Jakobson. We are also based on Lurian Neuropsychology and the Philosophy of Language developed by the Bakhtin Circle. The data presented and analyzed show, from the concept of inseparability between sound and meaning, the interdependence of linguistic levels and, beyond, the multidimensionality present in the network of links that underlies each word.
\end{abstract}

Keywords: aphasia; language; memory; tip-of-the-tongue; Word Finding Difficulties.

\section{Introdução}

A sensação de ausência ou inacessibilidade de uma palavra que desejamos encontrar é referida na literatura neuropsicológica e neurolinguística pela sigla WFD (Word Finding Difficulties), fenômeno que está presente tanto na normalidade quanto em algumas patologias que impactam o funcionamento da linguagem, tais como, a afasia e a demência. Em muitos casos, a sensação de saber a palavra que não vem pode estar presente, fenômeno sintetizado pelo termo Feeling of Knowing (FOK $)^{2}$. Junto com essa sensação, a iminência do aparecimento da palavra pode ser tão forte que nos referimos a esse estado como o da "palavra na ponta-da-língua" ou TOT (Tip-of-the-Tongue).

Mesmo que seja percebida de forma "consciente" pelo sujeito, nem sempre a falta da palavra pode ser resolvida no exato momento da enunciação, sem que se dê a suspensão do tópico discursivo. Frequentemente, essa ausência interrompe o fluxo natural do diálogo, impactando desde aspectos prosódicos - em decorrência de uma quebra na melodia e na cadência da enunciação - até os aspectos pragmático-discursivos. Por vezes, a falta de uma palavra acaba por engajar os outros parceiros na cena enunciativa, tal como se fosse uma espécie de jogo compartilhado em busca da palavra exata.

2 Utilizaremos a siglas WFD, TOT e FOK para nos referirmos aos respectivos fenômenos neste texto sempre que considerarmos desnecessário repeti-los por extenso. 
Tal dificuldade pode ser contornada com a produção de outra palavra com sentido semelhante ou pela reelaboração do enunciado por meio de paráfrases, mas isso vai depender de algumas variáveis, como o grau de formalidade da interação ou do gênero discursivo, a relevância da palavra para se chegar ao seu querer-dizer e, nas patologias, da severidade do caso. Esses processos ocorrem para que o sujeito possa alcançar a conclusibilidade de um intuito de dizer (cf. BAKHTIN, 1997). Todas essas questões, consequentemente, influenciam o grau de comprometimento do falante (e também dos interlocutores) para lidar com a necessidade e com a dificuldade de encontrar a palavra "exata".

Este trabalho tem como base teórica a Neurolinguística de orientação enunciativodiscursiva, abordagem que tem sido desenvolvida desde a década de 1980, inicialmente com o estudo sobre a linguagem nas afasias, a partir da tese de doutorado de Coudry, que discute os fenômenos linguístico-cognitivos a partir do estudo das afasias. Dentro deste escopo, a presente reflexão integra três campos de investigação científica, dentre os quais tem especial relevância a Linguística desenvolvida por Jakobson. Baseamonos também na Neuropsicologia Luriana e na Filosofia da Linguagem desenvolvida pelo Círculo de Bakhtin.

Esta articulação teórica se faz necessária dadas a complexidade e a amplitude do tema. De acordo com Novaes-Pinto (2009), a dificuldade para encontrar palavras, como conceito, engloba diferentes fenômenos e toma formas diversas quando associada a outros sinais (sintomas) das afasias. Para Souza-Cruz e Boccato (2017), as pesquisas desenvolvidas no âmbito da neurolinguística enunciativo-discursiva refletem como as trocas semântico-lexicais são recorrentes em enunciados de sujeitos com afasia, muitas vezes relacionadas às dificuldade de encontrar palavras. A tal estado podem se relacionar outros fenômenos, tais como, produção de parafasias, assim como a chamada "anomia" - incapacidade de nomeação de objetos e/ou ações, em situações de fala espontânea ou quando eliciados metalinguisticamente.

Ainda que, para o senso comum, essa dificuldade seja relatada como um esquecimento, como algo pertencente ao campo dos estudos sobre a memória, na ciência Linguística o tema tem sido abordado como uma falha no acesso lexical. Parte desta literatura pressupõe a compartimentalização da linguagem entre os níveis linguísticos como realidade psíquica, extrapolando o caráter abstrato do aparato analítico, próprio de modelos neuropsicológicos.

Neste sentido, devemos estar atentos que

[...] não podemos verdadeiramente isolar os elementos, mas tão somente distinguí-los. Se os tratarmos separadamente no processo de análise linguística, deveremos sempre lembrar-nos do caráter artificial de tal separação. Pode-se 
estudar o nível morfológico da linguagem fazendo abstração do nível fonológico. Pode-se estudar o nível formal sem referência ao nível semântico, e assim por diante. Mas entendemos que, agindo assim, tudo se passa como no caso de uma filtragem acústica - podem-se excluir, por exemplo, as altas frequências ou, pelo contrário, as baixas frequências - num caso e noutro, sabemos que se trata simplesmente de um método de experimentação científica. (JAKOBSON, 1981, p. 16).

Partindo de outro paradigma de pesquisa, de cunho qualitativo e dialógico, pretendemos demonstrar outros aspectos essenciais da dificuldade de encontrar palavras que não são levados em consideração em protocolos avaliativos nas situações artificiais de testagens em laboratório. A partir de dados emergentes no campo das patologias que impactam a linguagem, mais especificamente da afasia, recolhidos de situações de uso concreto da linguagem, refletiremos criticamente sobre a hierarquização e independência dos níveis linguísticos, principalmente no que diz respeito à separação entre um estágio semântico e outro fonológico, assim como também refletiremos sobre outros aspectos ligados à multidimensionalidade de enlaces que estão subjacentes às palavras.

\section{Os modelos de acesso lexical e a hierarquização dos níveis linguísticos}

Grande parte dos estudos sobre acesso lexical partem do pressuposto de que o processamento lexical se dá a partir da divisão entre os níveis linguísticos, separados hierarquicamente, conforme podemos ver na citação a seguir:

Como as palavras são acessadas durante produção da linguagem? As teorias sobre a produção da fala concordam em dois pontos fundamentais: (1) as informações de forma semântica, sintática e lexical constituem níveis independentes de representação e (2) esses níveis de representação provavelmente são acessados sequencialmente no curso da produção da linguagem. A visão dominante é que o acesso lexical envolve pelo menos dois estágios distintos de processamento. O primeiro estágio envolve a seleção de uma representação lexical semanti e sintaticamente específica, ou lema; o segundo estágio envolve a seleção da representação léxico-fonológica correspondente ou lexema. (CARAMAZZA, 1997, p. 77 , tradução nossa ${ }^{3}$.

\footnotetext{
3 No original: "How are words accessed in language production? Theories of speech production are in agreement on two fundamental points: (1) semantic, syntactic, and lexical form informations constitute independent levels of representation, and (2) these levels of representation are probably accessed sequentially in the course of language production. The dominant view is that lexical access involves at least two distinct stages of processing. The first stage involves the selection of a semantically and syntactically specified lexical representation or lemma; the second stage involves the selection of its corresponding lexical-phonological representation or lexeme".
} 
Conforme o autor (1977), neste ponto terminam as concordâncias entre os pesquisadores. Em quase todo o restante, desde a natureza da informação representada em cada estágio ou nível de processamento, o número geral de etapas de processamento, até a maneira pela qual as representações são selecionadas, há discordâncias substanciais entre os modelos. É importante ressaltar que, depois dessas separações, ainda há um série de subdivisões dentro de cada estágio, como, por exemplo, a divisão entre Lema e Lexema como níveis de representação lexical.

Com relação aos estudos das palavras na ponta-da-língua, desde o trabalho seminal de Brown e McNeill (1966), encontramos uma divisão sistemática entre as palavras relacionadas fonologicamente e aquelas relacionadas semanticamente com a palavraalvo. Os estudos posteriores em que se postulam esses níveis linguísticos como estágios influenciam diretamente a composição de modelos de acesso lexical que partem do pressuposto de que existe uma hierarquia estabelecida na retomada de uma palavra, conforme podemos ver abaixo:

O primeiro processo é um processo de recuperação semântica, pelo qual o falante ativa as informações semânticas apropriadas relevantes para o ato de fala pretendido. O segundo processo é de recuperação fonológica, em que a forma fonológica específica da palavra é acessada. [...] Embora as particularidades do modelo variem, no modelo básico geralmente aceito a retomada semântica vem primeiro, seguida pela retomada fonológica... (SCHWARTZ, 2002, p. 75, tradução nossa $)^{4}$.

Entretanto, considerando a ideia da "transmissão de informações" entre níveis linguísticos, hierarquicamente dispostos, um questionamento que podemos fazer é se realmente o acesso se daria em dois momentos, em que o primeiro se refere ao processamento semântico; e o segundo, ao fonológico, e se em algum momento essa ordem se inverteria. Um outro aspecto que deve ser considerado diz respeito à artificialidade de modelos que desconsideram a posição do ouvinte, como se a produção de uma palavra dependesse unicamente do falante e não respondesse a nenhuma pergunta.

Novaes-Pinto (1999, 2013), ao aproximar as ideias do Círculo de Bakhtin para o estudo das afasias, argumenta que, para Bakhtin, tanto a enunciação quanto os enunciados não podem ser explicados somente a partir das condições do sujeito falante, mas também não podem dele prescindir. Ou seja, não se pode compreender a enunciação destituída de uma situação concreta:

4 No original: "The first process is a semantic retrieval process, whereby the speaker activates the appropriate semantic information relevant to the intended speech act. The second process is a phonological retrieval process in which the particular phonological form of the spoken word is specifically accessed. [...] Although the particulars of the model vary, the basic model of semantic retrieval first, followed by phonological retrieval is generally agreed upon". 
Nos cursos de linguística geral (até nos cursos sérios como os de Saussure), os estudiosos comprazem-se em representar os dois parceiros da comunicação verbal, o locutor e o ouvinte (quem recebe a fala), por meio de um esquema dos processos ativos da fala no locutor e dos processos passivos de percepção e de compreensão da fala no ouvinte. Não se pode dizer que esses esquemas são errados e não correspondem a certos aspectos reais, mas quando estes esquemas pretendem representar o todo real da comunicação verbal se transformam em ficção científica. (BAKHTIN, 1997, p. 290).

Ainda para Novaes-Pinto (2009), a concepção de léxico como "lista de palavras" ou "dicionário mental" parece estar subjacente, enquanto modelo, à maioria dos trabalhos sobre memória semântica e sobre acesso lexical, mesmo na atualidade. Esta concepção de léxico "influencia ou limita o modo de entender o seu funcionamento, bem como a intrínseca relação do léxico com outros níveis linguísticos e com os demais processos cognitivos" (NOVAES-PINTO, 2009, p. 25).

Com o objetivo de explicitar o nosso questionamento sobre esses modelos que dissociam os aspectos semânticos dos fonológicos no funcionamento lexical, tendo em vista que estes modelos não correspondem à complexidade do WFD em situações de uso efetivo da linguagem, pretendemos, na próxima seção, tratar do conceito de palavra, que consideramos como central para essa discussão.

\section{O conceito de palavra e sua relação com estudos sobre acesso lexical}

Reflexões sobre o conceito de léxico e de palavra, relacionadas aos estudos neurolinguísticos, têm sido realizadas por Novaes-Pinto (2009), quando a autora se remete, dentre outros, aos estudos de Basílio (2004), que afırmam que o léxico abarca elementos que apresentam diferentes facetas: fonológicas, gráficas, morfológicas, sintáticas, semânticas, pragmáticas. Conforme observamos na seguinte passagem, 0 léxico não é um conjunto estático:

Como estamos sempre (re)produzindo e (re)conhecendo novos seres, objetos e relações, precisamos de um sistema dinâmico, capaz de se expandir à medida que se manifesta a necessidade de novas unidades de designação e construção de enunciados. [...] O léxico, portanto, não é apenas um conjunto de palavras. (BASÍLIO, 2004, p. 9).

Para Basílio, o potencial de atuação na formação de palavras não é necessariamente igual à formação concreta de novos itens, isto porque o léxico provê estruturas para "aproveitar qualquer palavra de uma classe para a formação de uma palavra equivalente em outra classe. Assim, todas as palavras de uma classe existiriam virtualmente nas 
outras classes. Mas só virtualmente, não na realidade" (BASÍLIO, 2004, p. 11). Este potencial confere dinamismo, considerando que algumas palavras efetivamente virão a existir, enquanto outras existem apenas enquanto potencial para vir a ser.

É relevante perceber, no Curso de Linguística Geral de Saussure, que a lexicologia não tem limites definidos com a morfologia e a sintaxe; estes campos linguísticos são descritos como interpenetrados. De acordo com Nunes (2006), essa interdependência posta por Saussure implica considerar que a divisão em níveis linguísticos é ilusória. O campo lexical, devido à sua natureza interdependente, é um local privilegiado para o estudo das relações entre o som e o significado, da proximidade entre os campos, das contradições, em contraposição ao estudo isolado e hierárquico, postulado nos modelos de acesso lexical da literatura tradicional.

Quanto à definição de palavra, Basílio (2004) nos leva a considerar diversos aspectos que apontam para a complexidade de uma unidade que, apesar de facilmente reconhecida pelos falantes, é de difícil definição. Se, do ponto de vista gráfıco, a palavra pode ser definida como uma "sequência de caracteres que aparecem no espaço e/ou pontuação e que corresponde a uma sequência de sons que formam uma palavra na língua" (BASÍLIO, 2004, p. 13), permanece o questionamento do que é "uma palavra da língua". A autora aponta para a necessidade de considerar aspectos estruturais, da especificidade morfológica, mas também aspectos que dizem respeito ao papel desta unidade na composição dos enunciados, além de outros, como os semânticos e fonológicos. Sendo assim, um dos problemas na definição do que seria uma palavra diz respeito à dificuldade de partir de um domínio preciso e não superposto.

Bakhtin (1997, p. 301) destaca que o léxico da língua é adquirido mediante "enunciados concretos que ouvimos e reproduzimos durante a comunicação verbal viva que se efetua com os indivíduos que nos rodeiam". De acordo com Bakhtin, toda palavra requer um movimento dialógico, de compreensão responsiva, que não pode prescindir de um outro, que the atualize. Para o autor:

As palavras são tecidas a partir de uma multidão de fios ideológicos e servem de trama a todas as relações sociais em todos os domínios. É portanto claro que a palavra será sempre o indicador mais sensível de todas as transformações sociais, mesmo daquelas que apenas despontam, que ainda não tomaram forma, que ainda não abriram caminho para sistemas ideológicos estruturados e bem formados. (BAKHTIN, 2006, p. 40).

Considerando-se que a palavra pode remeter tanto a uma parte quanto ao todo enunciativo, sendo sempre responsiva e dialógica, podemos afirmar que a dificuldade de encontrar uma palavra não se refere somente à procura de uma unidade abstrata, mas de uma unidade de sentido, concretamente ligada ao enunciado. 
Para Oliveira (2015), é essencial remeter a natureza dialógica da própria palavra no estudo dos TOTs (assim como do WFD e dos FOK, de maneira geral). O autor retoma a distinção entre signo e sinal, encontrada em Bakhtin (2006), para afirmar que a ausência da palavra, enquanto sinal, não apaga a multidão de fios ideológicos que a compõem como tal, já que, enquanto o signo se caracteriza pelo seu caráter indeterminado e pela sua ductilidade dentro da enunciação, o sinal é reiterável, unívoco.

De acordo com Luria (2001, p. 40), a palavra não somente referencia o objeto ou serve para a comunicação ou o pensamento, mas "consiste em um instrumento poderoso de análise deste mundo. Ao transmitir a experiência social relacionada com o objeto, a palavra nos leva além dos limites da experiência sensível". O autor também afırma que a interpretação da palavra como um rótulo não é suficiente ou adequada no campo dos estudos psicológicos, dado que a estrutura semântica da palavra é muito mais complexa. Nas palavras do autor:

[...] a palavra não somente gera a indicação de um objeto determinado, mas também, inevitavelmente, provoca a aparição de uma série de enlaces complementares, que incluem em sua composição elementos de palavras parecidas à primeira pela situação imediata, pela experiência anterior etc. Sendo assim, a palavra jardim pode evocar involuntariamente as palavras árvores, flores, banco, encontro etc., e a palavra horta, as palavras batata, cebola, pá etc. (LURIA, 2001, p. 45).

Para Luria (2001), cada palavra se situa como um elo de uma rede. Aquele que está numa conversação inibe ou contém toda esta rede de palavras para absorver o significado condizente com a situação e produzir a palavra desejada. Para o autor, o processo de determinação ou percepção de uma palavra deve ser encarado como um processo de escolha dentro de um "campo semântico" involuntariamente evocado. Neste sentido, a dificuldade de recordação de palavras e de denominação dos objetos pode estar relacionada mais com o excesso do que com a falta, ou seja, com a presença simultânea de palavras e conceitos que emergem involuntariamente para o sujeito, no momento da produção da linguagem. No entanto, essa rede que compõe cada palavra não é estritamente linguística. Luria (2001) afırma, a esse respeito, que por trás de cada palavra existem enlaces de naturezas diversas; sonoros, situacionais, afetivos e conceituais. "A palavra é uma rede potencial de enlaces multidimensionais" (LURIA, 2001, p. 82).

Nos estados inibitórios do córtex - como durante o sono, em situações de esgotamento ou em algumas patologias -, a capacidade de seleção de uma palavra, dentro de um mesmo campo associativo se altera, e os enlaces sonoros, situacionais e conceituais podem se tornar igualados, em termos de relevância. Com a seletividade alterada, a rede multidimensional das palavras se evidencia. Vejamos, por exemplo, um relato do mnemonista estudado por A. R. Luria que, talvez devido a sua memória espetacular, tinha um funcionamento diferente quanto à sinestesia presente nas palavras: 
O som de uma palavra tem uma forma e uma cor distintas, o significado outra forma e um peso particular, soa diferente... Para chegar na palavra certa no tempo certo, tenho que acomodar tudo isso. Por um lado, este procedimento traz complicações, mas por outro é uma maneira de recordar as palavras. (S, 1934 apud LURIA, 2006, p. 77).

Ainda para o autor (LURIA, 2001), o processo de retomada de uma palavra é complexo e ativo, pois passa por distinguir os sinais importantes e por inibir os não importantes, previamente codificados em matrizes multidimensionais, das quais dependem estruturas modais específicas (visuais, auditivas e tácteis), reunidas em estruturas integrais e dinâmicas.

As afasias, por excelência, dão visibilidade a essa constituição multidimensional dos enlaces, uma vez que podem "dissociar" essas interfaces, revelando aspectos do processo de seleção lexical. Na próxima seção nos aprofundaremos no pensamento de Roman Jakobson, autor que propôs, a partir dos eixos de funcionamento da linguagem ${ }^{5}$, uma forma de estudar a linguagem nas afasias. É importante ressaltar que, de acordo com Akhutina (2013), as ideias de Luria e Vygotsky se conectavam com as reflexões de Jakobson de maneira bilateral, naturalmente produtiva.

\section{As afasias e os eixos de funcionamento da linguagem}

De acordo com Coudry (1988), a afasia é uma alteração da linguagem decorrente de perturbações no Sistema Nervoso Central, de natureza focal, em virtude de acidentes vasculares cerebrais, traumatismos cranianos ou tumores. Ainda de acordo com a autora (1988, p. 5), "um sujeito é afásico quando, do ponto de vista linguístico, o funcionamento de sua linguagem prescinde de determinados recursos de produção ou interpretação". Também de acordo com a autora, a afasia exibe o funcionamento da linguagem em "câmera lenta", o que a torna um campo ainda mais privilegiado para compreender o funcionamento da linguagem.

Não se pode falar da contribuição da linguística nos estudos da afasia sem remeter a Jakobson. Para o autor, o estudo da linguagem compreendia tanto a linguagem em ato, quanto em evolução, em estado nascente e também em dissolução. O autor revoluciona o estudo da afasia ao refletir sobre dois eixos de funcionamento da linguagem. 0 eixo paradigmático está relacionado à seleção das unidades, dentre uma gama de elementos, enquanto o outro eixo, o sintagmático, se refere ao contexto de combinação dos elementos previamente selecionados. Estes eixos também podem contribuir significativamente para a compreensão dos fenômenos relativos às dificuldades de encontrar palavras, principalmente quanto consideramos sua interdependência, já que, para que ocorra a

5 Eixos que são referentes às operações propostas por Saussure (2001 [1916]). 
combinação, é necessário selecionar e, da mesma forma, toda seleção está subordinada ao contexto da combinação das unidades, que ocorre em todos os níveis linguísticos (JAKOBSON, 1981).

Segundo o autor, nos casos dos indivíduos afásicos, tal relação se caracterizaria pela predominância do funcionamento de um eixo sobre o outro, gerando os distúrbios de similaridade ou de contiguidade (JAKOBSON, 1981). As possibilidades de seleção e de combinação de unidades linguísticas estão correlacionadas, ainda, aos graus de liberdade do falante na produção dos enunciados, conforme vemos na seguinte passagem:

$\mathrm{Na}$ combinação de traços distintivos em fonemas, a liberdade individual do que fala é nula; o código já estabeleceu todas as possibilidades que podem ser utilizadas na língua em questão. A liberdade de combinar fonemas em palavras está circunscrita; está limitada à situação marginal da criação de palavras. Ao formar frases com palavras, o que fala sofre menor coação. E finalmente, na combinação de frases em enunciados, cessa a ação das regras coercitivas da sintaxe, e a liberdade de qualquer indivíduo para criar novos contextos cresce substancialmente, embora não se deva subestimar o número de enunciados estereotipados. (JAKOBSON, 1981, p. 39).

Se, por um lado, no que diz respeito à contextura, seja possível substituir uma palavra por outra de sentido semelhante, por outro, o falante tem pouca (ou nenhuma) liberdade para intervir na sua composição interna. Esses princípios de organização lexical podem nos ajudar a compreender tanto a busca incessante pela palavra (e a produção, por exemplo, de parafasias), quanto a desistência da busca, ao longo do processo.

Considerando que "cada signo é constituído de outros signos constituintes e/ou aparece em combinação com outros signos" (JAKOBSON 1981, p. 39), nossa unidade central de análise constitutiva do enunciado - a "palavra" - se dará tanto com relação aos seus elementos constitutivos internos (fonemas e unidades morfossintáticas), quanto com relação ao contexto maior do qual participa - os enunciados.

\section{As dificuldades de encontrar palavras, indo além do som e significado}

Diante do que foi exposto, apresentamos, a seguir, dois dados extraídos de episódios dialógicos com uma idosa afásica em que podemos observar não só a dificuldade de encontrar a palavra, mas também as estratégias de que ela lança mão para encontrar as palavras desejadas, revelando indícios do seu processo de busca.

Estes dados são recortes de diálogos que ocorreram na residência de SB, que somente são possíveis devido à relação de convivência entre os sujeitos. Neste caso, especificamente, 
acrescenta-se o fato de que BO e SB têm relacionamento familiar e se conhecem há muito tempo, antes de SB se tornar afásica. Por isso mesmo, existe grande conhecimento compartilhado entre ambos, o que também acaba possibilitando que SB atinja, em boa parte das vezes, seu "querer dizer". SB teve atendimento fonoaudiológico com BO nos anos de 2014 e 2015. O primeiro dado é proveniente de sessão fonoaudiológica com BO, já o segundo dado é um recorte videogravado de uma conversa em que a mesma me atualiza de suas dificuldades com a linguagem, já em 2019. Essas ocorrências ilustram o que entendemos por "dado singular" ou, na terminologia adotada por Coudry (1996), trata-se de um "dado-achado".

A interpretação destes dados se dá partir do aparato de análise microgenética, ou seja, em uma forma de conhecer que é orientada para as minúcias, detalhes e ocorrências residuais, como neste caso, de indícios não prototípicos que dão visibilidade ao fenômeno contemplado, na busca de desvelar os processos subjacentes à ausência e ao posterior surgimento das palavras. Como ressalta Goés (2000), essa análise não é micro em relação ao evento em si, mas sim a procura de minúcias indiciais não isoladas, articuladas em uma unidade.

O sujeito SB é uma senhora de 65 anos, afásica, que apresenta constantemente dificuldades de encontrar palavras. No ano de 2008 teve um Acidente Vascular Encefálico. Segundo tomografia computadorizada realizada em 29 de outubro de 2008, teve uma lesão de aspecto isquêmico em território vascular da artéria cerebral média esquerda, que acometeu os lobos temporal, parietal e porção anterior do lobo occipital homolateral. As principais características de sua afasia, de acordo com relatório fonoaudiológico, dizem respeito à anomia, apraxia e alteração no processamento auditivo.

No dia 18 de abril de 2015, SB falava comigo sobre sua irmã, que havia comprado um DVD pirata do filme "50 Tons de Cinza", com uma qualidade muito ruim, que não permitia ver o filme.

Quadro 1. Transcrição de dado registrado em diário

\begin{tabular}{|c|c|c|c|}
\hline Turno & Sujeitos & Enunciado & $\begin{array}{l}\text { Informações } \\
\text { contextuais }\end{array}$ \\
\hline 1 & SB & $\begin{array}{l}\text { - Olha, esse filme do cinza eu não vi. Eu preferi ver } \\
\text { outro filme. Aquele lá de Paris, sabe? }\end{array}$ & Fica hesitante... \\
\hline 2 & $\mathrm{BO}$ & - Sei não, diz aí qual é... & \\
\hline 3 & SB & $\begin{array}{l}\text { - Ah, porque esse aí que a J. comprou, como é } \\
\text { que diz... Do Árabe, sabe ? Olha, eu tenho que } \\
\text { falar "do Árabe" porque daí eu lembro do camelo, } \\
\text { daí eu chego no Camelô... Minha cabeça é tudo } \\
\text { misturado. }\end{array}$ & $\begin{array}{l}\text { J. é irmã de SB. } \\
\text { Ri bastante quando } \\
\text { diz camelô. }\end{array}$ \\
\hline
\end{tabular}




\begin{tabular}{|l|l|l|l|}
\hline $\mathbf{4}$ & BO & - Ah... Ela comprou o DVD pirateado ? & \\
\hline $\mathbf{5}$ & SB & $\begin{array}{l}\text { - Pois é. Muito ruim. Eu preferi ver outro filme... } \\
\text { daquele... Qual era o nome do gato da M. mesmo? }\end{array}$ & M. é esposa de BO. \\
\hline $\mathbf{6}$ & BO & $\begin{array}{l}\text { - O gordinho? Era Woody Allen. } \\
\text { - Isso, eu preferi ver Meia Noite em Paris, do Woody } \\
\text { Allen. }\end{array}$ & \\
\hline $\mathbf{7}$ & SB & - E gostou ? & $\begin{array}{l}\text { Balança a cabeça } \\
\text { positivamente. }\end{array}$ \\
\hline $\mathbf{8}$ & SB & - Adorei. Gosto muito dele. & \\
\hline
\end{tabular}

Fonte: Elaboração própria

Logo no início do episódio, quando, ao justificar que não quis ver um filme pirateado pela sua péssima qualidade, SB descreve seu percurso para chegar à palavra "camelô". Diz que precisa recorrer à palavra "árabe" (turno 3), associada à palavra "camelo", já que ambas compartilham um mesmo campo semântico de referências sócio-histórico-culturais. Por sua vez, a palavra "camelo" compartilha da mesma composição fonológica de "camelô, que é a palavra-alvo de SB para se referir ao vendedor de DVDs piratas, exceto pelo posicionamento do acento tônico oxítono nesta última. Retomando Jakobson, a seleção prévia da palavra árabe parece prever semelhança interna entre camelo e camelô.

No trabalho de doutorado (OLIVEIRA, 2015), apresentei um relato de palavra na pontada-língua em que um sujeito, sem nenhuma patologia que impacte a linguagem, deseja falar a palavra cabo-de-guerra, mas somente se recorda de queda-de-braço. Naquele momento, argumentei que as palavras guardavam, entre si, simultaneamente, tanto características fonológicas quanto semânticas, tornando difícil afirmar que tipo de enlace teria provocado o surgimento de uma palavra no lugar da outra, já que ambas são jogos competitivos e envolvem a noção de força, de disputa, ao mesmo tempo que possuem estruturas semelhantes, marcados pelo mesmo padrão silábico e posicionamento das sílabas tônicas, além do fato de que ambas são unidades lexicais compostas por duas palavras, ligadas pela preposição "de" e que possuem, na primeira palavra (cabo e queda), o mesmo posicionamento das oclusivas.

No dado que estamos analisando agora, não há a mesma percepção de simultaneidade entre a palavra inacessível e a palavra que surgiu no lugar desta, já que a retomada da palavra se dá sucessivamente. No entanto, é interessante refletir que previamente à associação semântica entre árabe e camelo, existe, para o sujeito, o reconhecimento da semelhança sonora entre camelo e camelô, o que nos permite questionar o direcionamento hierárquico proposto nos modelos referidos anteriormente durante a seleção lexical. Temos, assim, um dado que dá visibilidade ao imbricamento de aspectos semânticos 
e fonológicos que podem atuar, simultaneamente, tanto na dificuldade de encontrar a palavra, como também no processo de sua solução.

Mas ainda há outro ponto para analisar neste recorte. Embora SB não tenha dito o nome do filme que não viu, recorrendo à palavra cinza (turno 1), para chegar ao nome do filme a que preferiu assistir, remete a uma coincidência entre o nome do gato com o nome do diretor do filme, pois sabe que o animal tem o mesmo nome do diretor. Ou seja, mesmo sem recordar o nome do diretor nem do gato, se recorda que os dois têm o mesmo nome.

No próximo recorte, vamos ampliar as formas de busca de uma palavra a partir da análise de como a própria SB revela que descobriu uma palavra de que necessitava no meio de um encontro com as amigas. No dia 02 de maio de 2019, eu estava conversando com SB sobre as palavras que ela esquece com frequência, quando ela me disse, rindo, que tinha que contar a história do damasco.

Quadro 2. Recorte dialógico de dado videogravado

\begin{tabular}{|l|l|l|l|}
\hline Turno & Sujeitos & Enunciado & Informações contextuais \\
\hline 1 & Bo & Conta aí a história do Damasco... & Rindo \\
\hline 2 & SB & $\begin{array}{l}\text { Damasco foi assim... Eu tava na igreja, Ah! } \\
\text { Tinha tido um culto, tal, e a gente começou } \\
\text { a falar sobre fruta. Aí eu falei - Ah! eu gosto } \\
\text { tanto... Aí quando eu queria falar, aí eu } \\
\text { comecei, não... aquela fruta parecida com... } \\
\text { Pêssego, mas ela não é pêssego. Que no natal, } \\
\text { que no natal, no... perto do natal, ano novo, } \\
\text { tem aquela fruta, parece um pêssego mas } \\
\text { ela é um pouquinho mais amarela, parece } \\
\text { pêssego, assim, doce né? Ama, ama, amadura, } \\
\text { que o pêssego fica parecido, mas ela é mais } \\
\text { bonita e eu gosto daquela fruta, eu falava } \\
\text { com todo mundo: Você não sabe, ninguém } \\
\text { sabia, ninguém sabia... Aí, saí, pro cantinho, } \\
\text { aí comecei a ver na memória, assim. Passei } \\
\text { pelos árabes, como é? Porque agora tenho } \\
\text { essa dificuldade. Os árabes, é... Mas é, saiu, da } \\
\text { África. Síria fica na... }\end{array}$ & Faz cabeça de \\
descontentamento \\
Da Síria?
\end{tabular}




\begin{tabular}{|c|c|c|c|}
\hline 4 & SB & $\begin{array}{l}\text { Mas ele... Saiu, engraçado, se você pegar } \\
\text { um mapa vou te mostrar, que ele vai... Pelos } \\
\text { sírios, pelos árabes, aqueles árabes, não sei } \\
\text { quê dos árabes. A minha memória, ela vai, foi } \\
\text { direitinho, aquele mar azulzinho... que fica... }\end{array}$ & $\begin{array}{l}\text { Faz um gesto circular, } \\
\text { amplo, referindo-se ao } \\
\text { espaço do mar }\end{array}$ \\
\hline 5 & BO & Incrível! & \\
\hline 6 & $S B$ & $\begin{array}{l}\text { Como é que pode um negócio desses, né? Né } \\
\text { não, que eu vi... A Síria, aí logo Damasco. Ah, } \\
\text { Damasco! Voltei e falei pras meninas: Gente! o } \\
\text { nome da fruta era Damasco! }\end{array}$ & Gargalhando \\
\hline 7 & BO & & Risos \\
\hline 8 & SB & $\begin{array}{l}\text { Eu tive de ficar quietinha, porque, o negócio, } \\
\text { me dava querendo... saber, saber. Eu fui pra } \\
\text { um cantinho assim... A memória, ela... Eu } \\
\text { fiquei, esperando né? Ela foi, foi, foi... Aquele } \\
\text { azul, aquele mar azul, né? Aquele azul, aí... } \\
\text { Síria, Síria! Capital Damasco, pronto! Como é } \\
\text { que veio isso, gente? }\end{array}$ & $\begin{array}{l}\text { Estalando os dedos } \\
\text { Rindo junto com BO }\end{array}$ \\
\hline
\end{tabular}

Fonte: Elaboração própria

No dado anterior, o surgimento de Woody Allen por meio do esquecimento do nome do gato já nos dá a dimensão de que, indo além dos aspectos estritamente linguísticos, SB se utiliza da rede de enlaces subjacentes a cada palavra. Já neste dado, a rede multidimensional de enlaces subjacentes a cada palavra aparece de maneira mais clara, quase como em cenário.

No momento da ausência da palavra, no primeiro enlace - a palavra "pêssego" - tem maior evidência de relação semântica. A depender do interlocutor, esta pista já poderia ser eficiente para eliciar damasco. Contudo, neste caso específico, com a impossibilidade de chegar à palavra desejada, há uma riqueza de detalhes fornecidos por SB sobre a forma da fruta, ainda recorrendo aos interlocutores para chegar até a palavra. Entretanto, ninguém sabia chegar até a palavra a partir das pistas dadas por SB.

Posteriormente, SB sentiu a proximidade da palavra. A sensação de conhecer a palavra (FOK) e a de sua iminência caracterizam o fenômeno conhecido como TOT. SB não chega a dizer que a palavra está na ponta da língua, mas percebe que ela está se aproximando por um caminho que inicialmente não reconhece. SB decide "ir pro cantinho" e ficar "esperando", até que aquela palavra, nem totalmente lembrada nem totalmente esquecida, apareça. 
Considero, neste ponto, importante refletir sobre o imbricamento das funções psicológicas superiores, como proposto por Luria, mais especificamente com respeito à atenção. Para o autor (1981), a atenção é um processo ativo que depende de um funcionamento integrado de todo o cérebro, especialmente nas formas superiores da atenção, que, devido ao seu caráter voluntário, direcional, dependem da possibilidade de reconhecimento seletivo de determinado estímulo, que inclui a inibição de outros desnecessários. Devido à dificuldade de suspender o tópico discursivo com as amigas, SB afastou-se para direcionar sua atenção no processo metalinguístico de busca da palavra.

Durante tal processo, SB refaz um percurso retomando "árabes", chega a perguntar onde fica a Síria, possivelmente lembrando-se da Ásia. Além de toda a questão perceptual imagética, há ainda elementos ligados à história da palavra "Damasco", que se relacionam com o percurso imaginado por SB. Destaco a importância de refletir sobre as histórias singulares das palavras tanto na língua, na coletividade, quanto a história da palavra para cada indivíduo. Acho relevante pensar que, quando ouvi essa história desconhecia completamente que a capital da Síria era Damasco, no entanto, para SB, essa associação foi fundamental na retomada da palavra. De acordo com Oliveira (2015, p. 111), cada "palavra tem uma história dentro da língua, memórias que, em certa medida, são comuns aos sujeitos [...]. Por outro lado, há também uma história própria de cada sujeito com a palavra".

Finalmente, quase de forma eidética, ela visualiza um mar azul e então se recorda de que a capital da Síria é Damasco. Destaco aqui, considerando inclusive que SB remete a um mapa, ao azul associado ao mar Mediterrâneo (turnos 4 e 8), o papel que os elementos visuais prestam no percurso de SB para chegar à palavra. No relato, ela foi contar às amigas qual era a fruta e se impressionou com os (des)caminhos de sua memória: "como pode isso, gente?".

SB ri do percurso que ela mesmo fez para atingir parte fundamental do seu querer dizer. Faz parte do seu cotidiano lidar com diferentes caminhos, indícios. Em outros registros de diário, há momentos em que ela diz que precisa lembrar daquela palavra que parece francesa, que tem no prédio, e de repente diz "marquise". Em outro momento, pergunta qual o nome daquela pedra do "João Bosco" e cantarola a canção que me faz chegar até "Jade". De maneira geral, diz que sente a palavra se aproximando, tenta repetir o nome que às vezes vem e logo desaparece. Por fim, parece que aos poucos foi aprendendo a confiar nas reminiscências multidimensionais das palavras, decidindo como vale a pena buscá-las ou, até mesmo, esperar pelas suas chegadas.

\section{Considerações finais}

Neste artigo, refletimos sobre como a dificuldade de encontrar palavras se constitui em um fenômeno privilegiado para compreendermos nuances do funcionamento semântico- 
lexical, tais como, o imbricamento entre os níveis linguísticos durante a seleção de uma determinada palavra. A complexidade deste fenômeno em situações dialógicas concretas, sobretudo com sujeitos afásicos, permite entrever a multidimensionalidade de enlaces que estão subjacentes a cada palavra, conforme podemos perceber por meio da análise microgenética dos dados.

O estudo qualitativo das funções psicológicas superiores é desafiador, no entanto, assumir uma postura que valoriza o conhecimento qualitativo significa ir de encontro à maioria dos estudos contemporâneos, principalmente na área da neurolinguística. Este tipo de estudo tem papel fundamental para discutir possibilidades para além da separação e hierarquização dos níveis linguísticos, considerando que o campo lexical é um lugar em que se entremeiam características sonoras e semânticas (mas não somente estas) da palavra. Por fim, ressalto que a compreensão dos caminhos e estratégias encontrados para retomada (ou abandono) da palavra requerida é importante, sobretudo, na clínica fonoaudiológica que trabalha com as patologias que afetam a linguagem.

\section{REFERÊNCIAS}

AKHUTINA, T. V. Roman Jakobson and the Development of Russian Neurolinguistics. Journal of Russian and East European Psychology, v. 41, n. 3/4, p. 129-158, 2003.

BAKHTIN, M. Marxismo e Filosofia da Linguagem. 12. ed. São Paulo: Ucitec, 2006.

BAKHTIN, M. Estética da Criação Verbal. Tradução Maria Ermantina Galvão G. Pereira. 2. ed. São Paulo: Martins Fontes, 1997.

BASÍLIO, M. Teoria Lexical. São Paulo: Editora Ática, 2004.

COUDRY, M. I. Diário de Narciso: afasia e discurso. São Paulo: Martins Fontes, 2001.

COUDRY, M. I. O que é o dado em Neurolinguística. In: CASTRO, M. F. O método e o dado no estudo da linguagem. Campinas: Editora da UNICAMP, 1996.

BROWN, R.; MCNEILL, D. The "tip of the tongue" phenomenon. Journal of Verbal Learning and Verbal Behaviour, v. 5, n. 4, p. 325-337, 1966.

CARAMAZZA, A. How Many Levels of Processing Are There in Lexical Access? Cognitive Neuropsychology, v. 14, n. 1, p. 177-208, 1997. 
GOES, M. C. R. A abordagem microgenética na matriz histórico-cultural: Uma perspectiva para o estudo da constituição da subjetividade. Cadernos Cedes, ano XX, 2000.

JAKOBSON, R. Dois Aspectos da Linguagem e dois tipos de Afasia. In: JAKOBSON, R. Linguística e Comunicação. São Paulo: Cultrix, 1981.

LURIA, A. R. A mente e a memória: um pequeno livro sobre uma vasta memória. São Paulo: Martins Fontes, 2006.

LURIA, A. R. Pensamento e Linguagem: as últimas conferências de Luria. São Paulo: Ed. Artmed, 2001.

LURIA, A. R. Fundamentos de Neuropsicologia. São Paulo: Ed. da USP, 1981.

NOVAES-PINTO, R. C. As contribuições de conceitos desenvolvidos pelo Círculo de Bakhtin para a descrição e análise de enunciados de sujeitos com afasias. In: // Encontro de Estudos Bakhtinianos. Vida, Cultura, Alteridade: Caderno 2. São Carlos: Pedro e João Editores, 2013.

NOVAES-PINTO, R. C. Dificuldades de encontrar palavras e produção de parafasias nas afasias e nas demências: inferências para o estudo da organização e do acesso lexical. Projeto de Pesquisa Individual (CNPq) - Instituto de Estudos da Linguagem, Universidade Estadual de Campinas, Campinas, 2009.

NOVAES-PINTO, R. C. A contribuição do estudo discursivo para uma análise crítica das categorias clínicas. 1999. Tese (Doutorado em Linguística) - Instituto de Estudos da Linguagem, Universidade Estadual de Campinas, Campinas, 1999.

NUNES, M. H. Lexicologia e Lexicografia. In: GUIMARÃES, E.; ZOPPI, M. A palavra e a frase. São Paulo Ed. Pontes, 2006.

OLIVEIRA, M. V. B. Palavras na Ponta-da-língua: uma abordagem neurolinguística. 2015. Tese (Doutorado em Linguística) - Instituto de Estudos da Linguagem, Universidade Estadual de Campinas, Campinas, 2015.

SAUSSURE, F. Curso de Linguística Geral. C. Bally e A. Sechehaye (org.). 3. ed. São Paulo: Cultrix, 2001 [1916]. 
SCHWARTZ, B. L. Tip-of-the-tongue states: Phenomenology, mechanism, and lexical retrieval. Ney Jersey: LEA: 2002.

SOUZA-CRUZ, T. C.; BOCCATO, D. M. A. Produção de parafasias e paralexias e sua relação com as "Dificuldades de Encontrar Palavras" (Word Finding Difficulties). Estudos Linguísticos, São Paulo, v. 46, n. 2, p. 760-773, 2017. 